\title{
Neck, Shoulder, and Back Pain with Carrying Heavy Back Packs among the Spirit School Children in Lahore
}

\author{
Rubina Khan ${ }^{1}$, Hira Jabeen ${ }^{2}$, Hafiz Sheraz Arshad ${ }^{3}$ \\ ${ }^{1}$ Physical Therapist, Azra Naheed Medical College, Department of Physical Therapy, Main Raiwind Road, Lahore \\ ${ }^{2}$ Senior Lecturer, Azra Naheed Medical College, Department of Physical Therapy, Main Raiwind Road, Lahore
}

${ }^{3}$ Head of Department, Assistant Professor, Azra Naheed Medical College, Department of Physical Therapy, Main Raiwind Road, Lahore

\begin{abstract}
School children experience neck, shoulder and back pain due to carrying heavy bags. Heavy back packs negatively affect spine as well as cause other musculoskeletal symptoms. Objective: The aim of this study was to determine the frequency of neck, shoulder and back pain in spirit school children carrying heavy back packs. Method: This cross sectional survey was conducted among 135 students of private school in Pakistan, Lahore in 2016. Modified Nordic musculoskeletal questionnaire (Extended version) was used, asking about neck, shoulder and back pain and its details. Weights of the children were measured. Weights of bags were measured and its percentage with respect to body weight was also calculated. Results: Results showed that most prevalent musculoskeletal symptom was shoulder pain (44.4\%) followed by neck (29.6\%), low back (23\%) and upper back (3\%). Conclusion: Weight of school bags was strongly related to neck, shoulder and back pain in school children. Students who used double straps and carrying bags on both shoulder showed less symptoms.
\end{abstract}

Keywords: Children, school bag weight, shoulder pain, neck pain, posture

\section{Introduction}

\subsection{Overview}

Carrying heavy school bags is frequently related with many musculoskeletal discomforts(1). School children using improper method of carrying bags are at risk of musculoskeletal disturbances and tiredness.(2)It is stated that heavy school bags can alter the normal alignment of body by putting the body in stress condition(2)

Previous researches stated that the weight brought by school children is higher than the normal range. (3).Prolonged use of carrying heavy bags affect growing bones and causes stress injuries. While carrying back packs, it shifts the center of gravity of child in same direction as load. Child tilts himself opposite to the direction of weight to compensate this. For example, a child wearing bag on sacrum will precede the head and trunk in forward direction.(4)

Children between the ages of 12-14 years need special concerns because spine is yet at the stage of development. Children facing musculoskeletal disorders are highly associated with using heavy back packs as heavy bags can alter posture or body alignment. (3)

A study administered that there is significant alteration in body position, rate of perceived exertion and muscle strain. These occurs when school bag weight go up to $10 \%$ of body weight(5). This study investigated only the association of low back pain with carrying heavy school bags. It didn't explain other musculoskeletal disorders related to carrying high loaded school bags.

In present years, a greater involvement at school level is shown by the parents regarding heavy school bags.
Particularly parents revealed that problem as at individual level or through any organization. Furthermore, students as well as teachers have spoken out their level of discomforts or agitation related to heavy bags. These heavy bags put extra burden on children and responsible for fatigue.

Previous studies investigated the association of heavy bags with low back pain in school children. This research investigated three variables in relation to carrying heavy bags. It explored the occurrence of shoulder pain, neck pain and low back pain in school children due to carrying heavy bags.

\subsection{Objective}

The aim of this study was to determine the frequency of neck, shoulder and back pain in spirit school children carrying heavy back packs, low back pack or high back pack conditions pressure is at $10 \%, 20 \%$ and $30 \%$ of body weight on right and left shoulder is higher than that pressure which causes occlusion of cutaneous blood flow. (10)

\subsection{Rationale}

Outcome of this study will helpful in raising awareness regarding the effects of heavy back packs on neck, shoulder and back pain and would thus help developing preventive strategies of carrying school bags.

\subsection{Operational Definition}

\subsubsection{Nordic Questionnaire}

ModifiedNordic musculoskeletal questionnaire (Extended version) was used to assess pain (neck, shoulder and back pain).It is a questionnaire based tool which is used 


\section{International Journal of Science and Research (IJSR) \\ ISSN (Online): 2319-7064 \\ Index Copernicus Value (2013): 6.14 | Impact Factor (2015): 6.391}

for specifically neck, shoulder and back pain. It is to mention that it is not used for clinical diagnosis.Reliability of NMQ ranges from $0-23 \%$.Sensitivity of this tool is 66 $92 \%$ while specificity is between $71-88 \%$. (6)

\subsubsection{Weighing scale}

A digital weight scale CAMRY (modal EB 9320) was used for objective measurement of weight of bags and body weight of students.

\subsection{Material and Methods}

\subsubsection{Study Design}

This study was descriptive (cross sectional study).

\subsubsection{Duration}

This study was completed in estimated period of 3 months after the approval from ANMC research committee.

\subsubsection{Setting}

Data was collected from spirit schools Lahore.

Following schools was included in this study:

- The spirit school Wapda town Lahore.

- The spirit school Johar town Lahore

- The spirit school Faisal town Lahore

- The spirit school Riawind Road Lahore

\subsubsection{Sample size}

The sample size will be calculated using the online Raosoft sample size calculator.

$$
\begin{aligned}
X & =Z\left({ }^{c} / 100\right)^{2} r(100-r) \\
N & \left.=N x /{ }_{((N-1) E}^{2}+x\right) \\
E & =\operatorname{Sqrt}\left[{ }^{(N-n) x} / n(N-1)\right]
\end{aligned}
$$

In this formulan $=$ sample size, $\mathrm{E}=$ Margin of error, $\mathrm{N}=$ Population size, $r$ =fraction of responses, $\mathrm{Z}(\mathrm{c} / 100)=$ critical value for the confidence level c., In this sample size formula, we calculated sample size by taking following values:,E( margin of error) $=5 \%$, Confidence level: $95 \%, \mathrm{~N}=5000, \mathrm{r}=$ $90 \%$,It gave 135 as sample size.

\subsubsection{Sampling technique}

Simple random sampling technique

\subsubsection{Sample Selection}

\subsubsection{Inclusion criteria}

- School going students of class $5^{\text {th }}$ to $8^{\text {th }}$

- Carrying bags on one or both shoulders

- Both male and female students

- Ability to stand on weighing scale independently

\subsubsection{Exclusion criteria}

- Pathological, orthopedic or genetic causes of musculoskeletal symptoms.

- Metabolic or neoplastic disorders.

\subsubsection{Data Collection Procedure}

A descriptive cross sectional study was done in five spirit schools of Lahore during 2015 to 2016 including students of grade $5^{\text {th }}$ to $8^{\text {th }}$ grade. An informed consent firstly was taken from school administration by telling the aims and objectives of this study. The students were selected on the basis of simple random sampling technique.

Firstly questionnaire will record demographic information such as age, gender, class, type of school bags and carrying style of bag. Modified Nordic Musculoskeletal Disorders Questionnaire was used. It included human picture where respondent pointed out the areas of discomfort.

Questionnaire data was entered in SPSS version 21. Descriptive statistics and Frequency tables were used to analyze data.

\subsubsection{Participants Rights}

It was a cross sectional study. Students were voluntarily involved after an informed consent from students as well as teachers. It was not an experimental study so no treatment was applied on any student. Study had no any physical, social or psychological harm to students. All medical ethics were considered.

\section{Results}

Table 1: Frequency distribution of age, gender and school years among students:

\begin{tabular}{|c|c|c|c|}
\hline & & Frequency & Percentage \\
\hline \multirow{2}{*}{ Age } & $9-12$ & 72 & 53.3 \\
& $13-16$ & 63 & 46.7 \\
\hline \multirow{2}{*}{ Gender } & Male & 65 & 48.1 \\
& Female & 70 & 51.9 \\
\hline School & $5^{\text {th }}$ & 2 & 1.5 \\
year & $6^{\text {th }}$ & 53 & 39.3 \\
& $7^{\text {th }}$ & 39 & 28.9 \\
& 8 th & 41 & 30.4 \\
\hline
\end{tabular}

Mostly students (53.3\%) had ages between 9-12 years followed by $13-16$ years $(46.7 \%)$.Female students were more recruited $(52 \%)$ as compared to male (48\%).Most of the students were from $6^{\text {th }}$ class $(39.3 \%)$ with minimum value of $5^{\text {th }}$ class $(1.5 \%)$. All the participants responded back.

Table 2: Frequency distribution of body weight without

\begin{tabular}{|c|c|c|c|}
\multicolumn{4}{c}{ bags } \\
\hline & Groups & Frequency & Percentage \\
\hline \multirow{4}{*}{$\begin{array}{c}\text { Body weight } \\
\text { without bags }\end{array}$} & $21-30 \mathrm{~kg}$ & 10 & 7.4 \\
\cline { 2 - 4 } & $31-40 \mathrm{~kg}$ & 61 & 45.2 \\
\cline { 2 - 4 } & $41-50 \mathrm{~kg}$ & 44 & 32.6 \\
\cline { 2 - 4 } & $51-60 \mathrm{~kg}$ & 13 & 9.6 \\
\cline { 2 - 4 } & $61-70 \mathrm{~kg}$ & 7 & 5.2 \\
\hline
\end{tabular}

Most of the students (45.2\%) had body weight between 31$40 \mathrm{~kg}$ with minimum value $(5.2 \%)$ of $61-70 \mathrm{~kg}$.

Table 3: Frequency distribution of body weight with bags:

\begin{tabular}{|c|c|c|c|}
\hline & Groups & Frequency & Percentage \\
\hline \multirow{3}{*}{$\begin{array}{c}\text { Body } \\
\text { weight } \\
\text { with } \\
\text { bags. }\end{array}$} & $21-30 \mathrm{~kg}$ & 1 & .7 \\
\cline { 2 - 4 } & $31-40 \mathrm{~kg}$ & 36 & 26.7 \\
\cline { 2 - 4 } & $41-50 \mathrm{~kg}$ & 58 & 43.0 \\
\cline { 2 - 4 } & $51-60 \mathrm{~kg}$ & 30 & 22.2 \\
\cline { 2 - 4 } & $61-70 \mathrm{~kg}$ & 8 & 5.9 \\
\hline
\end{tabular}

Highest frequency (43\%) of weight between $41-30 \mathrm{~kg}$ (with bags) was measured and minimum frequency was of 21 $30 \mathrm{~kg}(0.7 \%)$.

\section{Volume 5 Issue 6, June 2016 www.ijsr.net}




\section{International Journal of Science and Research (IJSR) \\ ISSN (Online): 2319-7064 \\ Index Copernicus Value (2013): 6.14 | Impact Factor (2015): 6.391}

Table 4: Descriptive statistics for weight of bag and percentage of bag with respect to body weight:

\begin{tabular}{|c|c|}
\hline & Mean \pm SD \\
\hline Weight of bag & $5.74 \pm 1.298$ \\
\hline $\begin{array}{c}\text { Percentage of bag with respect } \\
\text { to body weight }\end{array}$ & $14.43 \pm 3.885$ \\
\hline
\end{tabular}

Mean \pm SD of weight of bag was 5.74 \pm 2.98 .Mean \pm SD of percentage of bags according to body weight was $14.43 \pm 3.885$.

Table 5: Frequency distribution of type of school bag $65.2 \%$ of school children use double strap bags while $34.8 \%$ use single strap bags

\begin{tabular}{|c|c|c|c|}
\hline $\begin{array}{c}\text { Type of } \\
\text { school } \\
\text { bag }\end{array}$ & Single strap & Frequency & Percentage \\
\cline { 2 - 4 } & Double strap & 87 & 34.8 \\
\hline
\end{tabular}

Table 6: Frequency distribution of reasons of carrying study material in school bags:

\begin{tabular}{|c|c|c|c|}
\hline \multirow{2}{*}{$\begin{array}{c}\text { Reasons of } \\
\text { carrying study }\end{array}$} & & Frequency & Percentage \\
\cline { 2 - 4 } material & His or her own choice & 61 & 45.2 \\
\cline { 2 - 4 } & Teachers & 36 & 26.7 \\
\cline { 2 - 4 } & According to schedule & 38 & 28.1 \\
\hline
\end{tabular}

Maximum school children (45.2\%) carried study material by their own choice.

$26.7 \%$ of students carried material because of their teachers.

Table 7: Frequency distribution of way of carrying bags

\begin{tabular}{|c|c|c|c|}
\hline \multirow{3}{*}{$\begin{array}{c}\text { Way of } \\
\text { carrying }\end{array}$} & & Frequency & Percentage \\
\cline { 2 - 4 } bags & on one shoulder & 66 & 48.9 \\
\cline { 2 - 4 } & on both shoulder & 68 & 50.4 \\
\cline { 2 - 4 } & rolling trolley by hand & 1 & .7 \\
\hline
\end{tabular}

$50.4 \%$ of students carry bags on both shoulder and $48.9 \%$ of students carry bags on one shoulder.

Table 8: Frequency distribution of lean forward posture during carrying bag:

\begin{tabular}{|c|c|c|c|}
\hline \multirow{2}{*}{$\begin{array}{c}\text { Lean forward during } \\
\text { carrying bags }\end{array}$} & \multicolumn{2}{|c|}{ Frequency } & Valid percent \\
\cline { 2 - 4 } & Yes & 56 & 41.5 \\
\cline { 2 - 4 } & No & 79 & 58.5 \\
\hline
\end{tabular}

$58.5 \%$ of students exhibited lean forward posture during carrying bags.

Table 9: Region wise frequency distribution of pain

\begin{tabular}{|c|c|c|}
\hline \multirow{2}{*}{ Region } & \multicolumn{2}{|c|}{ Ever had pain $(N=135)$} \\
\cline { 2 - 3 } & No & Yes \\
\hline Neck & $95(70.4 \%)$ & $40(29.6 \%)$ \\
\hline Shoulder & $74(54.8 \%)$ & $60(44.4 \%)$ \\
\hline Upper back & $131(97 \%)$ & $4(3 \%)$ \\
\hline Low back & $104(77 \%)$ & $31(23 \%)$ \\
\hline
\end{tabular}

Maximum students (44.4\%) showed shoulder pain.Least frequency $(3 \%)$ was shown in upper back pain.

Table 10: Frequency distribution of "have you any pain during last 12 months"

\begin{tabular}{|c|c|c|}
\hline \multirow{2}{*}{ Region } & \multicolumn{2}{|c|}{ Pain during last 12 months $(N=135)$} \\
\cline { 2 - 3 } & No & Yes \\
\hline Neck & $111(82.2 \%)$ & $24(17.8 \%)$ \\
\hline Shoulder & $103(76.3 \%)$ & $32(23.7 \%)$ \\
\hline Upper back & $130(96.3 \%)$ & $4(3 \%)$ \\
\hline Low back & $112(83 \%)$ & $23(17 \%)$ \\
\hline
\end{tabular}

During the last 12 months most of the participants had experienced pain in shoulder region $(23.7 \%)$. Least number of subjects $(3 \%)$ had experienced pain in upper back during last 12 months.

Table 11: Frequency distribution of "have you any pain during last 4 weeks"

\begin{tabular}{|c|c|c|}
\hline \multirow{2}{*}{ Region } & \multicolumn{2}{|c|}{ Pain during last 4 weeks $($ N=135) } \\
\cline { 2 - 3 } & No & Yes \\
\hline Neck & $96(71.1 \%)$ & $39(28.9 \%)$ \\
\hline Shoulder & $80(59.3 \%)$ & $55(40.7 \%)$ \\
\hline Upper back & $131(97 \%)$ & $4(3 \%)$ \\
\hline Low back & $105(77.8 \%)$ & $30(22.2 \%)$ \\
\hline
\end{tabular}

During the last 4 weeks most of the students (40.7\%) experienced pain in shoulder region .Least of participants showed pain in upper back (3\%) during last 4 weeks.

Table 12: Frequency distribution of "have you seen any clinician"

\begin{tabular}{|c|c|c|}
\hline \multirow{2}{*}{ Region } & \multicolumn{2}{|c|}{ Seen any clinician $(N=135)$} \\
\cline { 2 - 3 } & No & Yes \\
\hline Neck & $119(88.1 \%)$ & $16(11.9 \%)$ \\
\hline Shoulder & $121(89.6 \%)$ & $14(10.4 \%)$ \\
\hline Upper back & $133(98.5 \%)$ & $2(1.5 \%)$ \\
\hline Low back & $126(93.3 \%)$ & $9(6.7 \%)$ \\
\hline
\end{tabular}

Maximum students (12\%) had seen clinician due to neck pain. Only a few $(1.5 \%)$ students had seen clinician due to upper back pain.

Table 13: Frequency distribution of "have you taken medication because of pain"

\begin{tabular}{|c|c|c|}
\hline \multirow{2}{*}{ Region } & \multicolumn{2}{|c|}{ Taken medication(N=135) } \\
\cline { 2 - 3 } & No & Yes \\
\hline Neck & $115(85.2 \%)$ & $20(14.8 \%)$ \\
\hline Shoulder & $116(85.9 \%)$ & $19(14.1 \%)$ \\
\hline Upper back & $133(98.5 \%)$ & $2(1.5 \%)$ \\
\hline Low back & $121(89.6 \%)$ & $14(10.4 \%)$ \\
\hline
\end{tabular}

Most of students (14.8\%) had taken medications due to neck pain.Minimum students $(1.5 \%)$ had taken medications due to upper back pain.

\section{Conclusion}

This study concluded that weight of school bags was strongly related to neck, shoulder and back pain in school children. Students who used double straps and carrying bags on both shoulder showed less symptoms.

\section{Discussion}

This study showed the frequency of neck. Shoulder and back pain in school children due to carry heavy bags. A study was done in Tehran, Iran. Which showed the results which closely resembles to our research. That previous study showed that most common symptoms of musculoskeletal symptoms were shoulder pain $(38.1 \%)$,neck pain $(27.6 \%)$ and back pain $(16.7 \%$.) A study was done in 2015 which showed that $88.2 \%$ students showed neck, shoulder and back pain among musculoskeletal symptoms.(3)

Another study was done to find out musculoskeletal symptoms in school children. Study revealed that there was shoulder pain $(42.1 \%)$, neck pain $(24.5 \%)$, back pain

\section{Volume 5 Issue 6, June 2016}

www.ijsr.net

Licensed Under Creative Commons Attribution CC BY 


\section{International Journal of Science and Research (IJSR) \\ ISSN (Online): 2319-7064}

Index Copernicus Value (2013): 6.14 | Impact Factor (2015): 6.391

(35.7\%).This percentage was very similar to our findings. Moreover in our studies as well as studies in other countries showed that shoulder pain is more prevalent in school going children.(14).

In our study it has been seen that children who carry weight of bags less than $10 \%$ of BW also experience neck, shoulder and back pain. In addition our research findings match with a research conducted in Iran (15). Same conclusion was find previously in a study done in 2015 (Drzal-Grabiec et al., 2015). Another study was done in Iran to find out safe limit of weight of bags.It was suggested that the current limit of weight of bags (10-15\% of body weight) is not a safe limit to carry bags. (Drazal-Grabiec et al.,2015).Prevention is better than treatment. Parents should check the bags on daily bases. Second line of prevention should start from school level. Children should be provided with lockers to keep their bags and other materials to prevent from discomforts. In addition choose the right bag with respect to body weight and comfortable level, skip unnecessary items, choose padded double straps and carry on both shoulders.

This study is limited to Lahore population. Rural children are not getting involved in this study. It does not represent these musculoskeletal symptoms in rural population. Finally there is no comparison between rural and urban school going children.

It does not describe the exact safe limit of weight of bags with respect to BW.So further studies should be done to evaluate safe limits of weight of bags.

Another limitation of this study is it is a cross sectional study. There is no evaluation of association of cause and effect. Therefore results are the general demonstration of problem.

\section{References}

[1] Dockrell S, Simms C, Blake C. Schoolbag carriage and schoolbag-related musculoskeletal discomfort among primary school children. Appl Ergon. 2015;51:281-90. Epub 2015/07/15.

[2] Arghavani F, Zamanian Z, Ghanbary A, Hassanzadeh J. Investigation of the relationship between carrying school bags (handbags and backpacks) and the prevalence of musculoskeletal pains among 12-15 year old students in Shiraz. Pak J Biol Sci. 2014;17(4):550-4.

[3] Mwaka ES, Munabi IG, Buwembo W, Kukkiriza J, Ochieng J. Musculoskeletal pain and school bag use: a cross-sectional study among Ugandan pupils. BMC research notes. 2014;7(222):1756-0500.

[4] Mwaka ES, Munabi IG, Buwembo W, Kukkiriza J, Ochieng J. Musculoskeletal pain and school bag use: a cross-sectional study among Ugandan pupils. BMC research notes. 2014;7:222. Epub 2014/04/10.

[5] Dianat I, Javadivala Z, Allahverdipour H. School Bag Weight and the Occurrence of Shoulder, Hand/Wrist and Low Back Symptoms among Iranian Elementary Schoolchildren. Health Promot Perspect. 2011;1(1):7685.

[6] Crawford JO. The Nordic Musculoskeletal Questionnaire. Occupational Medicine. 2007;57(4):3001 .
[7] Drzal-Grabiec J, Snela S, Rachwal M, Podgorska J, Rykala J. Effects of carrying a backpack in an asymmetrical manner on the asymmetries of the trunk and parameters defining lateral flexion of the spine. Human factors. 2015;57(2):218-26. Epub 2015/04/08.

[8] Afzal N, Asim HM, Dilshad H. Frequency of Low Back Pain due to Heavy Bags among School-going Children in Lahore, Pakistan.

[9] Shamsoddini A, Hollisaz M, Hafezi R. Backpack weight and musculoskeletal symptoms in secondary school students, tehran, iran. Iranian journal of public health. 2010;39(4):120-5. Epub 2010/01/01.

[10] Macias BR, Murthy G, Chambers H, Hargens AR. Asymmetric loads and pain associated with backpack carrying by children. Journal of pediatric orthopedics. 2008;28(5):512-7. Epub 2008/06/27.

[11] Dockrell S, Kane C, O'keefe E. Schoolbag weight and the effects of schoolbag carriage on secondary school students. Ergonomics. 2006;9:216-22.

[12] Korovessis P, Koureas G, Papazisis Z. Correlation between backpack weight and way of carrying, sagittal and frontal spinal curvatures, athletic activity, and dorsal and low back pain in schoolchildren and adolescents. Journal of spinal disorders \& techniques. 2004;17(1):33-40.

[13] Negrini S, Carabalona R. Backpacks on! Schoolchildren's perceptions of load, associations with back pain and factors determining the load. Spine. 2002;27(2):187-95.

[14] Arghavani F, Zamanian Z, Ghanbary A, Hassanzadeh J. Investigation of the Relationship Between Carrying School Bags (Handbags and Backpacks) and the Prevalence of Musculoskeletal Pains among 12-15 Year Old Students in Shiraz. Pakistan Journal of Biological Sciences. 2014;17(4):550.

[15] Dianat I, Javadivala Z, Asghari-Jafarabadi M, Asl Hashemi A, Haslegrave CM. The use of schoolbags and musculoskeletal symptoms among primary school children: are the recommended weight limits adequate? Ergonomics. 2013;56(1):79-89.

\section{Author Profile}

Rubina Khan is Physical therapist, Azra Naheed Medical College, Department of Physical Therapy, Main Raiwind Road, Lahore

HiraJabeen is Senior Lecturer, Azra Naheed Medical College, Department of Physical Therapy, Main Raiwind Road, Lahore

Hafiz SherazArshad is Head of department/Assistant professor, Azra Naheed Medical College, Department of Physical Therapy, Main Raiwind Road, Lahore 